\title{
Effect of passivator DHJ-C on the growth and cadmium accumulation of Brassica napus in Cd-contaminated soil
}

\author{
Xin Wang ${ }^{\dagger}$,, Qian Liu ${ }^{\dagger}$, Yunbao Wan, Chenxi Cao, Jiuyuan Bai, Rui Wang and Yun Zhao*
}

\begin{abstract}
The farmland polluted by cadmium is increasing drastically, which seriously threatened agricultural production and food safety. Nowadays, efficient and convenient way to solve the problem is urgently needed. In this experiment, a particular compound passivator DHJ-C was applied for soil remediation by pot experiment and the effect on both soil and plant was evaluated. The $\mathrm{DHJ}-\mathrm{C}$ reduced the toxicity of $\mathrm{Cd}$ on soil enzyme activity and growth inhibition on Brassica napus. The soil urease and sucrase activity were significantly increased. The dry weight of mature oilseed rape increased by $14.6-36.0 \%$ and the yield of seeds increased by $14.1-52 \%$ per plant, which suggested that the passivator effectively reduced the detrimental effects on rape. Similarly, the results of physiology and biochemistry also indicated that DHJ-C can distinctly alleviate the inhibitory effect of $\mathrm{Cd}$ on plant growth. Such as the MDA content in plant was reduced by $52.1 \%$ in $10 \mathrm{mg} / \mathrm{kg} \mathrm{Cd}$ treatment. Compared with control, Cd accumulation in seedling stage and mature period was significantly reduced as the concentration of $\mathrm{Cd}$ in aboveground part even decreased by 18.4 and 32.0\% respectively. Overall, DHJ-C hold sufficient ability to be applied as an excellent passivator to reduce Cd toxicity in contaminated soil and significantly increase the yield of rapeseed.
\end{abstract}

Keywords: Cadmium, Soil pollution, Oilseed rape, Passivator, Stress responses

\section{Introduction}

Soil is a vital substrate and environmental basis for agricultural production. However, large amounts of heavy metals flowed into farmland due to various anthropogenic agricultural and industrial activities in recent years. For example, mining and smelting activities, fertilization application and sewage irrigation, etc., are the major sources of excess heavy metals (especially cadmium) in soil [1]. The high mobility of cadmium (Cd) make it easily entry into plant through the root-soil interface, reduce the absorption of nutrients, consequently aggravate the degree of lipid peroxidation and inhibit plant photosynthesis. Besides this, $\mathrm{Cd}$ can easily transfers into human

\footnotetext{
*Correspondence: zhaoyun@scu.edu.cn

${ }^{\dagger}$ Xin Wang and Qian Liu authors contributed equally to this work Key Laboratory of Bio-Resource and Eco-Environment of Ministry of Education, College of Life Sciences, Sichuan University, Chengdu 610065, China
}

body through the food chain and concentrates in bone, liver and kidney, which brings potential risks of serious illnesses even cancer [2]. Huang et al. [3] found that root length, leaf area and root tip growth of three pepper cultivars were significantly inhibited under cadmium stress in hydroponic condition. The significant reduction of root length, stem length and dry weight of potato seedlings under Cd stress was also found by Hassan et al. [4]. Withal, due to the same transport system between heavy metals and plant essential elements, $\mathrm{Cd}$ significantly inhibited the uptake of plant nutrients, and most of the plant growing in $\mathrm{Cd}$-contaminated soil showed certain symptoms of nutritional deficiency [5].

More than that, $\mathrm{Cd}$ has complex effects on the physiological and biochemical characteristics of plant. The photosynthetic system can be destroyed by reducing chlorophyll and carotenoid content in plant, as well as oxidative phosphorylation in mitochondria [6, 7]. Xue et al. [8] demonstrated that total chlorophyll, net 
photosynthetic rate and stomatal conductance of soybean seedling leaves decreased significantly under Cd stress. Through the years, a lot of evidence further proved that heavy metal can cause severe oxidative stress in plant and produced a large amount of reactive oxygen species (ROS), which is one of the initial biochemical changes against $\mathrm{Cd}$ stress. These oxidative stresses stimulate and enhance the activity of various enzymes and non-enzymatic antioxidant systems in cells, thus eliminating excessive oxygen free radicals and protecting plant from toxicity, such as superoxide dismutase (SOD), peroxidase (POD), catalase (CAT), glutathione reductase (GR), etc. Leon et al. [9] found that $\mathrm{Cd}$ stress could enhance the activity of CAT, SOD and GPX (glutathione peroxidase) in pepper leaves. Similarly, the increased activity of SOD and POD in pea seedlings was also observed by previous study [10], while decreased with respect to CAT. Finally, from the above, the normal growth and development of plant, crop yield and food safety are all greatly affected, which has aroused major concerns.

On the current situation, many practices have been conducted to remediate soil contamination. The main methods contain physical, chemical and biological method. Among them, chemical method is a kind of rapid and efficient in-situ repair method. It mainly makes use of certain passivating agents to reduce the mobility and availability of heavy metals in soil and simultaneously ensure soil remediation and agricultural production. Therefore, this approach is considered as an ideal repair method. Up to now, the most commonly used and recognized passivators include lime materials, coal fly, phosphates, biochar, compost products and mineral components. The research conducted by Sheng et al. [11] and Fuentes et al. [12] indicated that coal fly could change $\mathrm{pH}$ value and reduce the concentration of exchangeable heavy metals in soil. Li et al. [13] revealed that red mud based passivator could reduce $\mathrm{Cd}$ concentration in each part of the rice plant and simultaneously transform the exchangeable fraction into other unavailable fractions along with the raised $\mathrm{pH}$ value in soil. However, most of the current researches focus on the physicochemical traits and passivating mechanisms of diverse passivators. Changes in plant response against heavy metals after application of passivating agents has rarely been reported, which is directly crucial for plant growth and guiding the practical application of passivators.

In present study, a kind of compound passivator $\mathrm{DHJ}-\mathrm{C}$ was employed. In order to illuminate the effect of passivator DHJ-C on Brassica napus L. in Cd contaminated soil, we conducted an outdoor pot experiment under a cascade concentrations of cadmium stress. The main purpose of this study is to study the effect of different $\mathrm{Cd}$ stress on soil enzyme activity and the physiological response of Brassica napus, and further evaluate the remediation effect with the application of combined passivator DHJ-C in the contaminated soil, which can be helpful for further practices of soil remediation and agricultural production.

\section{Materials and method}

\section{Soil, passivator and rapeseed cultivar}

The soil used in the experiment was loam soil and bought from Sansheng Town, Chengdu City, Sichuan Province in China. The basic physical and chemical properties were showed in Table 1. Passivator was provided by the Laboratory of Microbial Technology and Environmental Pollution Remediation, College of Life Science, Sichuan University. It mainly consists of bentonite, phosphate, silicon fertilizer, straw power and NPK (nitrogen, phosphorus and potassium) compound fertilizer. The $\mathrm{pH}$ value is $7.07 \pm 0.09$ and no $\mathrm{Cd}$ has been detected $(<0.1 \mathrm{mg} / \mathrm{kg})$. Popular commercial variety of rapeseed, Keleyou1, was applied as plant material, which was provided by our own laboratory.

\section{Soil treatment}

The mixed soil was naturally air-dried and divided into five groups of the same quality. $\mathrm{CdCl}_{2}$ solution was added to each group and stirred uniformly to simulate contaminated soil with $\mathrm{Cd}$ ion concentrations of $0,2.5,5,7.5$, and $10 \mathrm{mg} / \mathrm{kg}$, respectively. The $\mathrm{Cd}$ contaminated soil was placed indoors for 30 days. Each group of stabilized $\mathrm{Cd}$ contaminated soil was divided into two parts on average. A composite passivator material with a mass ratio of $2.5 \%$ was added to the experimental group one week before planting, and the mixture was stirred and mixed, and no passivating agent was set as control group. The ten sets of soil treatments obtained were separately put into pots, and each treatment was triplicate.

Table 1 Physical and chemical properties of tested soil

\begin{tabular}{|c|c|c|c|c|c|c|}
\hline Treatment & $\mathrm{pH}$ & Organic matter (g/kg) & Total nitrogen $(\mathrm{g} / \mathrm{kg})$ & $\begin{array}{l}\text { Total phosphorus } \\
\text { (g/kg) }\end{array}$ & $\begin{array}{l}\text { Total potassium (g/ } \\
\mathrm{kg})\end{array}$ & $\begin{array}{l}\text { Total cadmium (mg/ } \\
\mathrm{kg} \text { ) }\end{array}$ \\
\hline Untreated & $7.90 \pm 0.02$ & $140.197 \pm 15.746$ & $5.097 \pm 0.486$ & $1.756 \pm 0.021$ & $18.349 \pm 0.439$ & $0.177 \pm 0.01$ \\
\hline $\mathrm{DHJ}-\mathrm{C}$ & $7.78 \pm 0.05$ & $152.223 \pm 18.161$ & $7.112 \pm 0.507$ & $1.836 \pm 0.112$ & $21.850 \pm 0.696$ & $0.168 \pm 0.01$ \\
\hline
\end{tabular}

The data in the table are mean \pm standard deviation $(n=3)$ 


\section{Brassica napus cultivation and sample collection}

Keleyou1 seeds with full grain, uniform size and no pests were selected to soak in sterile water for $30 \mathrm{~min}$, and then soaked one day at room temperature for germination after $52{ }^{\circ} \mathrm{C}$ incubation in water for $20 \mathrm{~min}$. The germinated seeds were sown in the different treatments and placed outdoors. Plants grew from November to May next year in nylon net room. Temperature conditions were consistent with local climate. Soil moisture was maintained at $70 \%$ as the field's water holding capacity. In the four-leaf stage, 5 seedlings were sampled, and the remaining 5 materials were grown and sampled at maturity stage in each treatment. The second leaf from bottom to top of seedling was used to determine various biochemical indexes. The whole plant material was divided into roots and shoots, rinsed with tap water and deionized water, and dried at $70{ }^{\circ} \mathrm{C}$ until constant weight. At the same time, the soil was sampled at depth of 5-10 cm from each pot around the seedlings and airdried. The roots, shoots and seeds of the mature plant were washed with tap water and deionized water, respectively, and dried at $70{ }^{\circ} \mathrm{C}$ until constant weight for further determination.

\section{Physical and chemical properties of the soil}

According to the method of Weng et al. [14], we determined the physical and chemical properties of the soil. The soil was mixed by $\mathrm{CO}_{2}$-free water in a ratio of 1:2.5. PHSJ-3F pH meter (Shanghai Ray Magnetic) was used for $\mathrm{pH}$ determination. Determination of organic matter content, total nitrogen content and total potassium content was based on the methods previously described by Sun et al. [15] and $\mathrm{Yu}$ et al. [16], respectively. And the total phosphorus content was measured according to ammonium molybdate colorimetry [17].

\section{Enzyme activity determination}

Soil urease was determined by the colorimetric method as described previously by Caruso et al. [18]. and the sucrase was determined by the 3,5-dinitrosalicylic acid colorimetric method, and the procedure was described with reference to Liang et al. [19]. As for the determination of antioxidant enzyme activity in plant, $0.1 \mathrm{~g}$ of fresh seedling leaves were mixed with $1 \mathrm{~mL}$ PBS solution, then homogenized on ice and centrifuged at $8000 \mathrm{~g}$ for $4 \mathrm{~min}$ at $4{ }^{\circ} \mathrm{C}$. The supernatant was extracted as crude enzyme solution. The activity of the superoxide dismutase (SOD), catalase (CAT) and peroxidase (POD) were assayed using the SOD/CAT/POD KIT (Suzhou comin Biotechnology Co.Ltd, China). Xanthine oxidase oxidizes the xanthine substrate to produce superoxide anion $\left(\mathrm{O}^{2-}\right)$, $\mathrm{O}^{2-}$ reduced blue formazan formed by nitroblue tetrazolium, and the product has an absorption peak at $560 \mathrm{~nm}$. SOD can effectively remove $\mathrm{O}^{2-}$, so the darker blue of the reaction solution indicates that the SOD activity is lower. An enzyme activity unit (U) is defined as the enzyme activity of SOD at a $50 \%$ inhibition percentage in the above-mentioned xanthine oxidase coupling reaction system. The catalase (CAT) activity was determinated by monitoring the change of the absorbance of $\mathrm{H}_{2} \mathrm{O}_{2}$ at $240 \mathrm{~nm}$ wavelength in a unit reaction time. The one unit (1U) of enzyme activity of CAT is defined as: degradation of $1 \mathrm{nmol} \mathrm{H}_{2} \mathrm{O}_{2}$ per minute per gram of leaf tissue.

The specific absorption at $470 \mathrm{~nm}$ wavelength represents the catalysis of POD enzyme to $\mathrm{H}_{2} \mathrm{O}_{2}$. The variation of absorption in unit time reflects the POD enzyme activity. The 0.01 absorbance change at $470 \mathrm{~nm}$ wavelength per minute in $1 \mathrm{~mL}$ of the reaction system per gram of leaf tissue was defined as an enzyme activity unit.

\section{Chlorophyll content determination}

Chlorophyll content was determined by acetone ethanol mixture method [20]. The fresh rapeseed leaves were washed under distilled water and was blotted up by filter paper. $0.06 \mathrm{~g}$ leaves were weighed and cut, then quickly placed in $10 \mathrm{~mL}$ extracting solution $(80 \%$ acetone and $95 \%$ ethanol with volume ratio $1: 1$ ) and incubated in $30{ }^{\circ} \mathrm{C}$ incubator for $24 \mathrm{~h}$ in the dark. The absorbance was measured at 645 and $663 \mathrm{~nm}$ wavelength, and the blank extracting solution was set as control. Each sample determinated three times. The formula is as follows:

$$
\begin{aligned}
& \text { Total Chlorophyll Content }(\mathrm{mg} / \mathrm{g})= \\
& \left(20.2 \mathrm{D}_{645}+8.02 \mathrm{D}_{663}\right) \times \mathrm{V} /(1000 \times \mathrm{W}) .
\end{aligned}
$$

\section{Malondialdehyde (MDA) content determination}

The determination of MDA content utilizes the thiobarbituric acid (TBA) method. $0.2 \mathrm{~mL}$ of crude enzyme solution was added in $0.6 \mathrm{~mL}$ of TBA reaction solution in a $1.5 \mathrm{~mL}$ centrifuge tube. The reaction mixture was bathed in $95{ }^{\circ} \mathrm{C}$ water for $30 \mathrm{~min}$. After immediately cooling on ice, the mixture was centrifuged at $10,000 \mathrm{~g}$ for $10 \mathrm{~min}$ at $25{ }^{\circ} \mathrm{C}$. Then the supernatant was extracted and the absorbance was measured at $532 \mathrm{~nm}$ and $600 \mathrm{~nm}$ wavelength. The equation is as follows:

$$
\begin{aligned}
& \text { MDA content }(\mathrm{nmol} / \mathrm{g} \text { fresh weight }) \\
& =25.8 \times(\mathrm{A} 532-\mathrm{A} 600) / \mathrm{W} .
\end{aligned}
$$




\section{Cd content determination}

The content of the $\mathrm{Cd}$ was measured according to the national standard HJ786-2016 in China. The dried plant samples were ground to powder. $0.2 \mathrm{~g}$ sample was mixed with $600 \mu \mathrm{L}$ distilled water and $5 \mathrm{~mL}$ of concentrated hydrochloric acid in a $50 \mathrm{~mL}$ of Teflon crucible, and then shaken slightly. All digestion processes were carried out in a fume hood. First, the sample was heated to $120^{\circ} \mathrm{C}$ until the remaining liquid in the crucible was lower than $3 \mathrm{~mL}$. After cooling down slightly, $5 \mathrm{~mL}$ of concentrated nitric acid, $5 \mathrm{~mL}$ of hydrofluoric acid and $3 \mathrm{~mL}$ of high chlorine were sequentially added. Then the mixture was capped and heated at $160{ }^{\circ} \mathrm{C}$ for $1 \mathrm{~h}$. After that, the lid was opened and the temperature of the hot plate was raised to $170{ }^{\circ} \mathrm{C}$. The crucible was shaken from time to time. When the digestion mixture emitted thick white smoke, covered the crucible until the black organic matter on the wall disappeared and then opened the lid. Continue heating to drive the white smoke until the liquid in the crucible steamed to a viscous shape. When the sample was thoroughly digested, transferred the liquid to $1 \mathrm{~mL}$ of concentrated nitric acid after cooled to about $50{ }^{\circ} \mathrm{C}$. When the solution cooled to room temperature, transferred it to a $15 \mathrm{~mL}$ centrifuge tube and dilute to $10 \mathrm{~mL}$ with distilled water for testing. The $\mathrm{Cd}$ content was determined by flame atomic absorption spectrophotometry. In the process of digestion and determination, the national standard bush leaves (GBW07603) was used for quality control.

\section{Data analysis}

The experimental data was statistically analyzed using Excel 2013 and SPSS 25.0, and the Origin 2017 was used for mapping. One-way ANOVA were applied first and treatment means were compared using least significant difference (LSD) multiple comparison analysis at a significance level of $p=0.05$ for any significant differences using SPSS 25.0, and the significance between treatments was marked by different lowercase letters $(p<0.05)$.

\section{Results}

\section{Soil enzyme activity}

Soil enzyme activity is an important index to reflect soil fertility and rhizosphere microbial activity in soil, which is of great significance to agricultural production. In the absence of heavy metals, the soil urease activity of the treatment group applied with the passivator was significantly higher than that of the group without passivator (Fig. 1a), indicating that the addition of the passivator may increase the soil nitrogen fertility and organic matter content, which results in a significant increase in urease activity. Once suffering from Cd stress, the soil urease activity in both treatments was significantly reduced, and the control group decreased by $30 \%$ under $2.5 \mathrm{mg} / \mathrm{kg} \mathrm{Cd}$, which suggested that urease is very sensitive to $\mathrm{Cd}$ stress. Although the soil urease activity in two groups were stable under different concentrations of $\mathrm{Cd}$, the urease activity in experimental group was significantly higher than that of the control, which indicated that the inhibitory effect of $\mathrm{Cd}$ on soil urease was reduced by DHJ-C.

Figure $1 \mathrm{~b}$ shows the soil sucrase activity in different $\mathrm{Cd}$ treatments. Similar to urease activity, the addition of passivator significantly increased soil sucrase activity compared to the control in all $\mathrm{Cd}$ treatment. The soil sucrase activity increased firstly and then decreased in both two
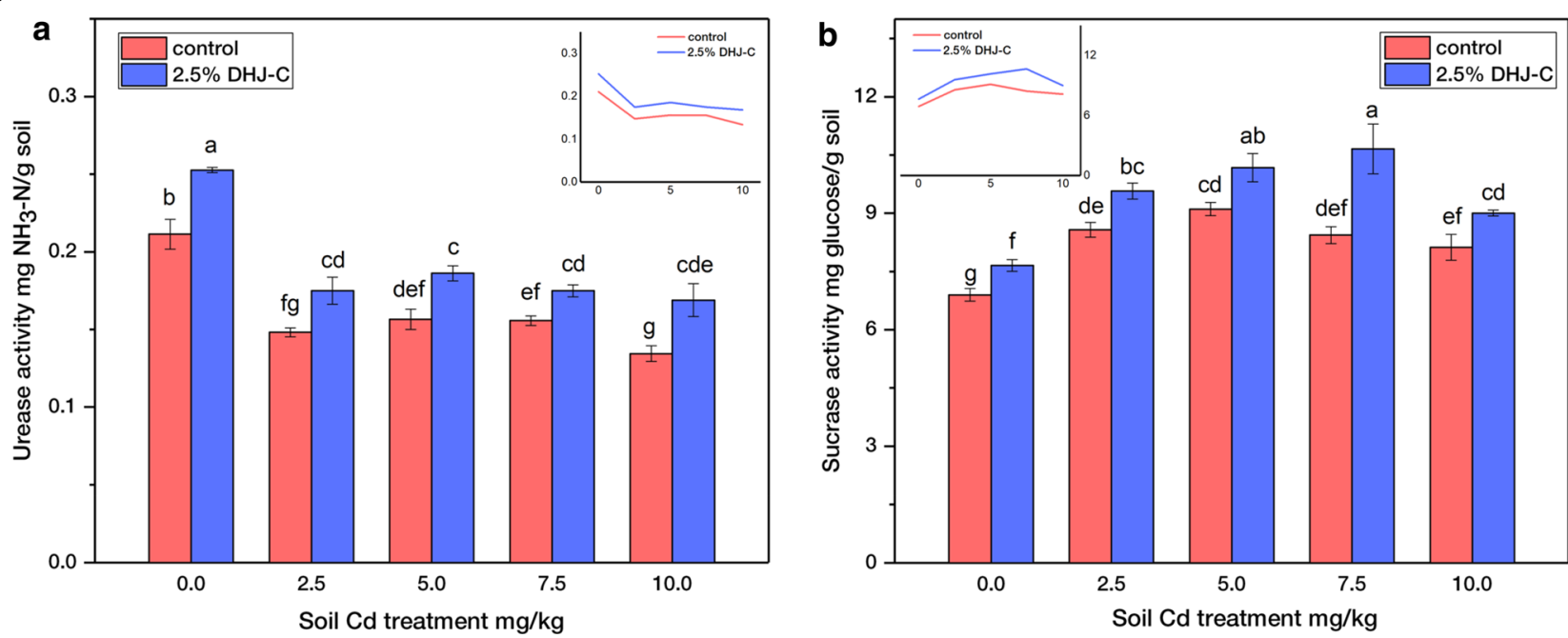

Fig. 1 Enzyme activity in rhizosphere soil of four-leaf seedling oilseed rape. a urease activity; $\mathbf{b}$ sucrase activity. Significance analysis was conducted by LSD multiple comparison analysis. Different lower case letters above the column indicate significant difference among treatments $(p<0.05)$. Error bars indicate standard error based on three independent biological replicates 

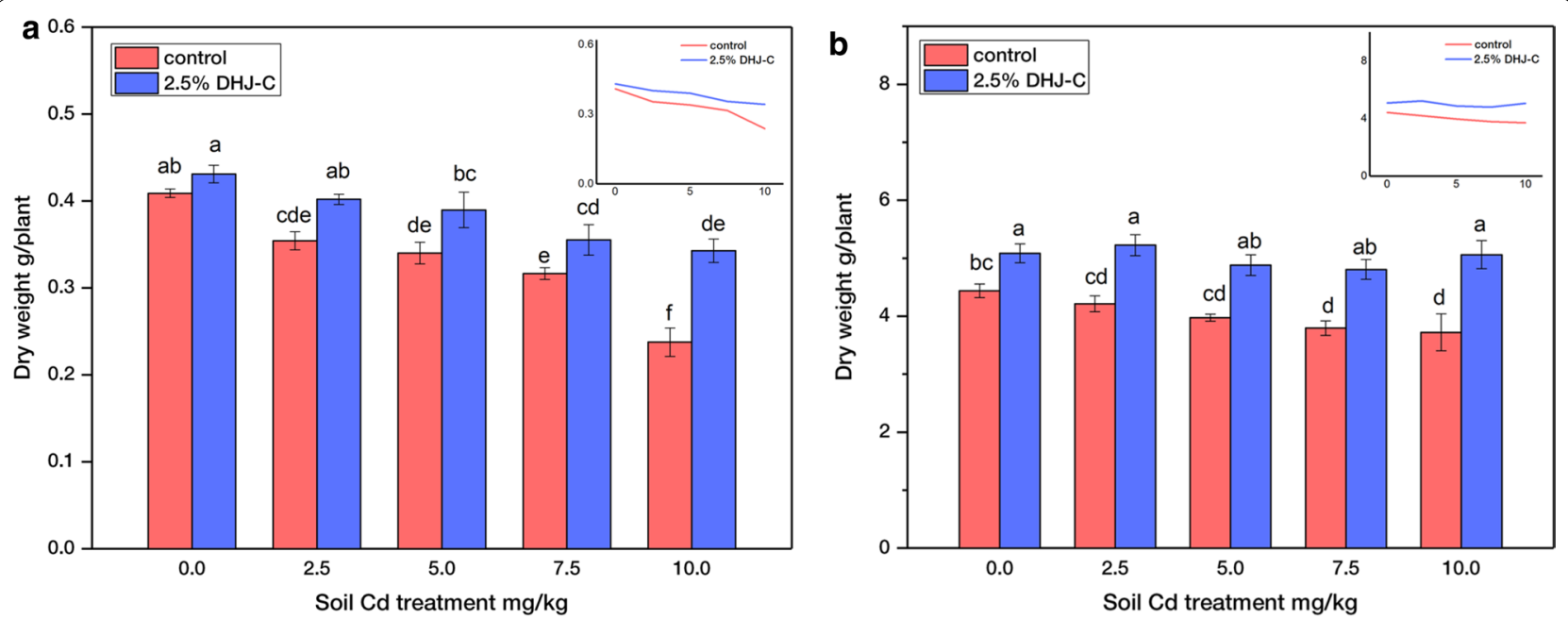

Fig. 2 Dry weight of oilseed rape. a four-leaf seedling dry weight; $\mathbf{b}$ mature plant dry weight. Significance analysis was conducted by LSD multiple comparison analysis. Different lower case letters above the column indicate significant difference among treatments $(p<0.05)$. Error bars indicate standard error based on three independent biological replicates

groups, which indicated that the medium and low concentrations of $\mathrm{Cd}$ stress can promote the soil invertase activity, while high concentration of Cd shows inhibiting effect. In the experimental group, compared with $7.5 \mathrm{mg} / \mathrm{kg}$ Cd treatment, soil sucrase activity showed a significant decrease (15\%) in $10 \mathrm{mg} / \mathrm{kg}$ treatment, which showed a distinct hysteresis compared with the control that reduced in $7.5 \mathrm{mg} / \mathrm{kg}$ treatment. Thus the application of DHJ-C can effectively delay and reduce the toxic effect of cadmium, and to some extent improve the efficiency of carbohydrate decomposition and utilization in soil.

\section{Physiological indexes of oilseed rape}

Physiological indicators can indicate the growth status of plant. Dry weight of seedlings and mature plant is shown in Fig. 2a, b. Obviously, a significantly increase can be seen when DHJ-C is added in both four-leaf stage and maturity stage. At the seedling stage, the dry weight of rapeseed decreased under the increasing $\mathrm{Cd}$ stress in two groups, but the degree of reduction in treatment group was significantly lower than control. The dry weight of oilseed rape in the experimental group was increased by $44.3 \%$ compared with the control at high concentration of $\mathrm{Cd}(10 \mathrm{mg} / \mathrm{kg})$. Unlike seedlings, the dry weight of mature plant under different $\mathrm{Cd}$ treatments had no such obvious difference within two group itself, but the dry weight in the experimental group was significantly higher than the control group under all treatments of $\mathrm{Cd}$ concentration $(0-10 \mathrm{mg} / \mathrm{kg})$ which increased by $14.6,24.0,22.9 \% 26.7 \%$ and $36.0 \%$, respectively. This result indicated that the addition of passivator DHJ-C could promote the growth

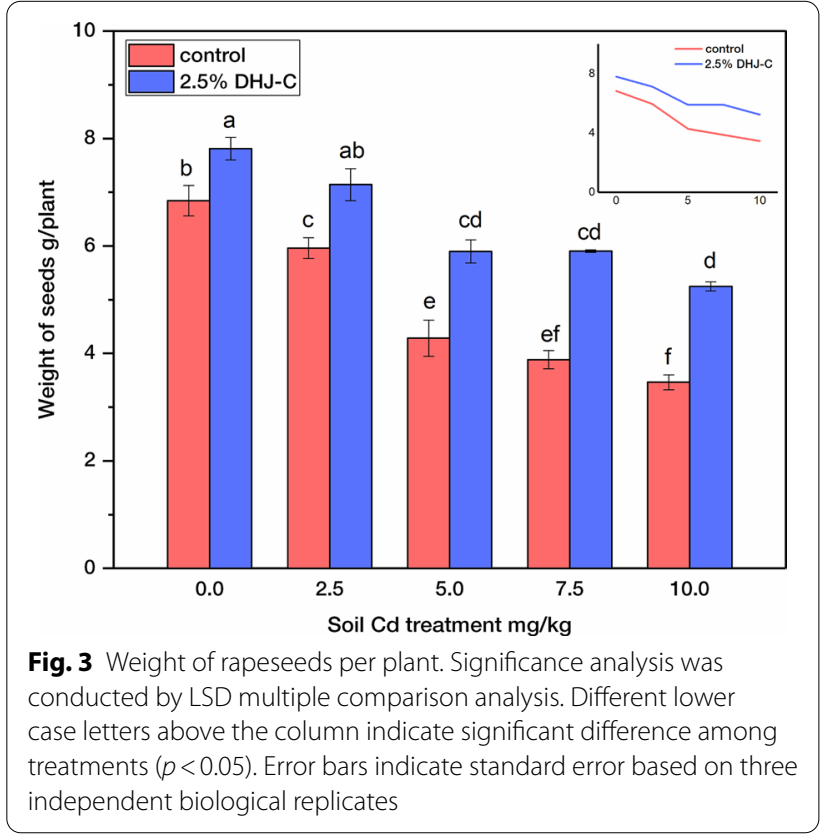

of the rape in both two stage, especially under the stress of high concentration of $\mathrm{Cd}(10 \mathrm{mg} / \mathrm{kg})$. The promotion effect of passivator was lasted from seedling to mature stage, which may be due to the long-term effect on the growth of rape, reduce the toxicity of $\mathrm{Cd}$ and enhance the biomass of crops in the whole growth period.

The weight of seeds determines the yield of rape and is critical for its economic value. It can be seen from Fig. 3 that $\mathrm{Cd}$ stress significantly reduced average seed weight per plant in two groups. Compare with non-Cd 
treatment, the seeds weight in control group decreased by $22,37,43$ and $49 \%$ with the increase of Cd concentration $(2.5-10 \mathrm{mg} / \mathrm{kg})$ respectively. However, the seeds weight increased by $14.1-52.1 \%$ with the addition of DHJ-C under different $\mathrm{Cd}$ treatments. These results indicate that the passivator can reduce the toxic effect of $\mathrm{Cd}$ and enhance the yield of rapeseed.

Chlorophyll is the main functional component for photosynthesis in plant, whose content can reflect the level of photosynthesis to some extent. In this experiment, chlorophyll content reached the peak with the Cd concentration of $5 \mathrm{mg} / \mathrm{kg}$ in both two group. Compare to the control, the usage of $\mathrm{DHJ}-\mathrm{C}$ increased the chlorophyll content of the plant in the high $\mathrm{Cd}$ concentration (>=5 mg/kg), especially in $10 \mathrm{mg} / \mathrm{kg}$ treatment (Fig. 4). Notably, under the Cd stress of $10 \mathrm{mg} / \mathrm{kg}$, the total chlorophyll content of oilseed rape in control group was $30 \%$ lower than that under $7.5 \mathrm{mg} / \mathrm{kg}$, while only $4.7 \%$ reduction in the experiment group with the addition of passivating agent. Thus, the application of passivator effectively alleviated the toxic effects of $\mathrm{Cd}$.

\section{Antioxidant enzymes activity}

Antioxidant system is a vital defensive line for plant to resist external stress. It can protect plant from oxidative damage by removing active oxygen free radicals generated by oxidation. According to Fig. $5 \mathrm{a}$, b, with the increase of $\mathrm{Cd}$ treatment, the SOD activity and CAT activity of seedlings increased first and then decreased. Under low concentration of $\mathrm{Cd}(\leq 5 \mathrm{mg} / \mathrm{kg})$, no significant difference in SOD activity between two groups was

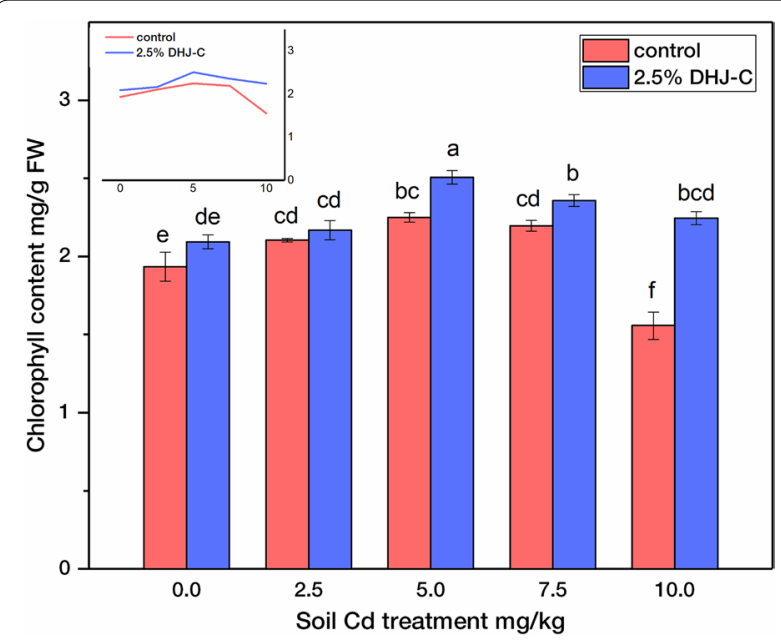

Fig. 4 Chlorophyll content in four-leaf seedling oilseed rape. Significance analysis was conducted by LSD multiple comparison analysis. Different lower case letters above the column indicate significant difference among treatments $(p<0.05)$. Error bars indicate standard error based on three independent biological replicates observed. However, with the application of DHJ-C, both the SOD activity and the CAT activity were significantly higher than the control with $\mathrm{Cd}$ concentrations of 7.5 and $10 \mathrm{mg} / \mathrm{kg}$. It can be deduced that the plant antioxidant system is activated with low concentration of $\mathrm{Cd}$ so that the activities of SOD and CAT are induced, and obviously SOD is more sensitive. However, high concentration of $\mathrm{Cd}$ caused severe damage to plant antioxidant enzymes and inhibited the activity of SOD and CAT. The passivator DHJ-C has an efficacious mitigation of this destructive effect and enhances the resistance to external stress.

With the increase of Cd concentration, the activity of POD enzyme increased steadily under the two groups, while the activity of POD was visibly lower in the passivator group than in the control under high Cd stress ( $>5 \mathrm{mg} / \mathrm{kg}$ ), which suggested that POD may play an important role in detoxification at high $\mathrm{Cd}$ concentrations. Compared to control group, the activity of POD in $7.5 \mathrm{mg} / \mathrm{kg}$ and $10 \mathrm{mg} / \mathrm{kg} \mathrm{Cd}$ treatment was reduced by $40 \%$ and $15.4 \%$, respectively (Fig. $5 \mathrm{c}$ ), which indicated that $\mathrm{Cd}$ stress activates the POD enzyme of plant, and the addition of passivation agent significantly alleviated the stress in high $\mathrm{Cd}$ concentration.

MDA content is positively correlated with the extent of oxidative damage. The MDA content of oilseed rape leaves increased significantly under $\mathrm{Cd} 10 \mathrm{mg} / \mathrm{kg}$ treatment without DHJ-C, while there was no notably difference in $2.5-7.5 \mathrm{mg} / \mathrm{kg} \mathrm{Cd}$ treatment (Fig. $5 \mathrm{~d}$ ), indicating that high concentrations of $\mathrm{Cd}$ caused severe damage to seedling. Unlike the increase in control group, the MDA content unexpectedly decreased with $10 \mathrm{mg} / \mathrm{kg}$ Cd treatment. Compared with treatment and control group, the addition of DHJ-C even reduced the MDA content by $53 \%$. Therefore, it can be concluded that $\mathrm{Cd}$ aggravates the activity of the membrane peroxidation in rapeseed and stimulates the antioxidant system. However, high concentrations of $\mathrm{Cd}$ also destroyed the antioxidant system and reduced the activity of several antioxidant enzymes. The application of passivator DHJ-C efficiently protected the antioxidant system of oilseed rape and reduced the toxicity of $\mathrm{Cd}$.

\section{Cd accumulation in oilseed rape}

Reducing $\mathrm{Cd}$ accumulation in plant is one of the most important goals of soil remediation. The Cd content in aboveground part and root raises steadily whether in four-leaf stage or mature stage (Fig. 6). In the four-leaf stage, the enrichment concentration of $\mathrm{Cd}$ in the root and aerial part reached 4.77 and $5.69 \mathrm{mg} / \mathrm{kg}$ respectively under the treatment of $10 \mathrm{mg} / \mathrm{kg} \mathrm{Cd}$ in control group. In all the experimental groups, compared with control, the passivation agent reduced the cadmium content in the aboveground and underground parts by $11.5-20.8 \%$ 

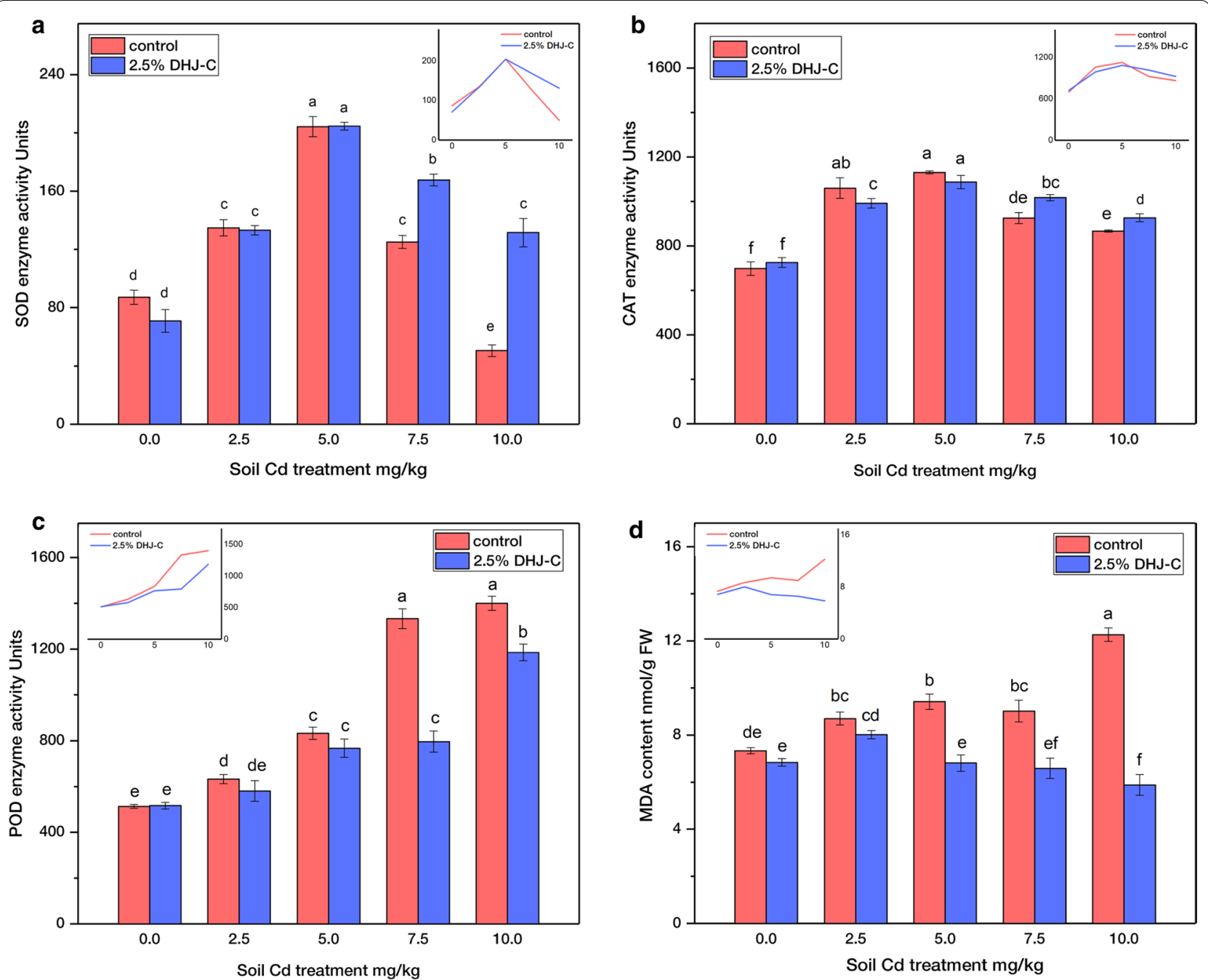

Fig. 5 Antioxidant enzyme activity and MDA content in four-leaf seedling oilseed rape. a SOD enzyme activity; b CAT enzyme activity; c POD enzyme activity; $\mathbf{d}$ MDA content. Significance analysis was conducted by LSD multiple comparison analysis. Different lower case letters above the column indicate significant difference among treatments $(p<0.05)$. Error bars indicate standard error based on three independent biological replicates

and $8.5-18.4 \%$ in the seedling stage, respectively. Similar to plant in the four-leaf stage, cadmium content in plant grow in step with it in soil and DHJ-C also effectively reduced cadmium in mature plant. Especially in the roots of the mature rapeseed, the content of the $\mathrm{Cd}$ was $52.1 \%$ lower than that of the control in $10 \mathrm{mg} / \mathrm{kg} \mathrm{Cd}$ treatment. It is worth noting that the application of DHJ-C effectively reduces the $\mathrm{Cd}$ content in all treatments. The determination of $\mathrm{Cd}$ in seeds is lower than the lower limit of detection in all treatments $(<0.1 \mathrm{mg} / \mathrm{kg})$, which is also far lower than $\mathrm{Cd}$ limit in food and oil. The above results demonstrate that the addition of passivator significantly reduces the enrichment of $\mathrm{Cd}$ in plant.

\section{Discussion}

Recent studies have found that some soil enzymes are very sensitive to heavy metal stress and can be used as indicators of soil environmental quality, such as urease and sucrose, catalase, and so on [21, 22]. Therefore, the enzyme activity can be used as a manifestation of soil fertility and soil pollution level. Meanwhile, soil pollution status can be evaluated easily, quickly and accurately by soil information system constructed by enzyme activity. In this experiment, soil urease and sucrase activities were used to characterize soil fertility and biological activity. The results showed that soil urease activity was significantly lower under $\mathrm{Cd}$ treatment than that of unstressed treatment, but there was no conspicuous difference under 

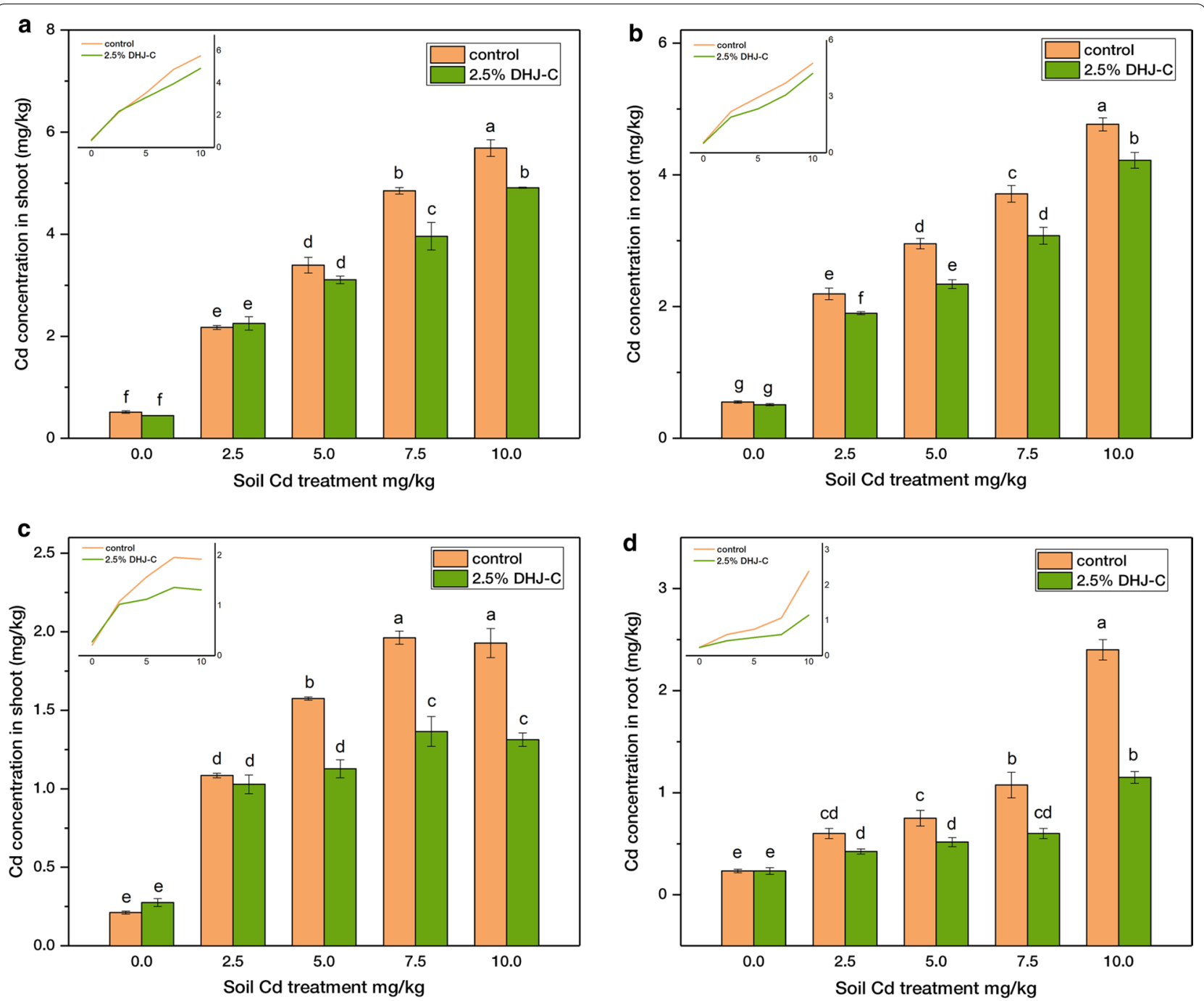

Fig. $6 \mathrm{Cd}$ content in seedling and mature oilseed rape. a $\mathrm{Cd}$ concentration in shoot of four-leaf seedling; $\mathbf{b} \mathrm{Cd}$ concentration in root of four-leaf seedling; $\mathbf{c}$ Cd concentration in shoot of mature plant; $\mathbf{d}$ Cd concentration in root of mature plant. Significance analysis was conducted by LSD multiple comparison analysis. Different lower case letters above the column indicate significant difference among treatments $(p<0.05)$. Error bars indicate standard error based on three independent biological replicates

diverse Cd stress $(2.5-10 \mathrm{mg} / \mathrm{kg})$, while the invertase activity increased first and then decreased (Fig. 1). It follows that urease is more sensitive to Cd stress and more suitable as an indicator of soil pollution. Compared with the control, the activities of urease and sucrase were significantly improved under $\mathrm{Cd}$ stress, indicating that the addition of DHJ-C can reduce the toxic effect of $\mathrm{Cd}$ on soil biological activity. Even under no Cd stress, DHJ-C also increased soil urease and sucrase activity, signifying the $\mathrm{DHJ}-\mathrm{C}$ can increase soil fertility and biological activity to some extent.

It is universally accepted that $\mathrm{Cd}$ in the environment can be absorbed by the plant, which will cause a series of toxic effects on plant, including cell and organelle structure destroy, inhibiting the absorption of nutrients by plant, destroying the ion balance in plant, and producing peroxidative stress. Ultimately, it will reduce the photosynthesis efficiency of the plant, inhibit normal growth and development, and thus lead to a decline in the quality and yield of agricultural products. Mohamed et al. [23] found that under $\mathrm{Cd}$ stress conditions, the fresh weight and dry weight of Brassica juncea at seedling stage were significantly reduced, and the root length and leaf area were also affected. Similar findings have also appeared in Brassica napus during various stages [24-26]. According to Fig. 4, under Cd stress, the chlorophyll content of rapeseed at seedling stage showed a gradual increase at low concentration $(\leq 5 \mathrm{mg} / \mathrm{kg})$, but decreased under 
high concentration stress, especially in control treatment. This phenomenon indicates that low concentration of Cd stress can promote the synthesis of chlorophyll in rapeseed and increase the photosynthesis and metabolism of plant, which may be due to plant stress response or metal ion co-transport. However, high concentration of Cd destroys the structure and synthesis of chlorophyll and inhibits photosynthesis efficiency of plant, declining the biomass of the plant (Fig. 2). After the addition of DHJ-C, the growth inhibition caused by Cd was limited, especially under high concentration stress. And the yield shows the same phenomenon that deteriorate seriously under high Cd treatment (Fig. 3).

Heavy metal causes oxidative stress in plant, which produces a large amount of oxygen free radicals (ROS), destructing the balance of ROS in cells and resulting in oxidative damage. The enzyme antioxidant system in plant can scavenge ROS to reduce oxidative damage. Similar to previous study [27], the activity of SOD and CAT increased gradually under the stress of $0 \sim 5 \mathrm{mg} /$ $\mathrm{kg} \mathrm{Cd}$ and decreased significantly under the stress of 5-10 mg/kg Cd (Fig. 5a, b), indicating that low concentration of $\mathrm{Cd}$ induced the antioxidant system in rapeseed, but high concentration of $\mathrm{Cd}$ caused excessive superoxide radicals and do harm to the antioxidant system. Combined with the result of MDA (Fig. 5d), we can also find that as the increase of $\mathrm{Cd}$, the degree of lipid peroxidation in rapeseed also increases significantly. However, the activity of POD enzyme continued to increase under the stress of $0-10 \mathrm{mg} / \mathrm{kg} \mathrm{Cd}$ (Fig. $5 \mathrm{c}$ ). It can be speculated that POD enzyme is important in the resistance metabolism of rapeseed under $\mathrm{Cd}$ stress, and it can maintain high activity and continue to normally function. With the addition of the DHJ-C, not only the MDA content was reduced, but also the SOD, CAT and POD enzyme activities were significantly enhanced (Fig. 5). This may be due to the fact that the $\mathrm{DHJ}-\mathrm{C}$ can reduce the Cd damage in the plant.

Cadmium can bring negative effects on both plant seed germination, growth and yield [28]. The Cd content in crops is closely related to food safety. Over the past $5 \mathrm{dec}-$ ades, 22,000 tons of $\mathrm{Cd}$ has been released into the environment. Surprisingly, $82 \%-94 \%$ of the cadmium entered into the soil [29]. For the strong migration of Cd, it is easy to be absorbed and accumulated by plant [30]. Therefore, it is urgent to find practical measures to ensure crop safety in polluted areas, so as to ensure crop production and food safety. As shown in Fig. 6, the accumulation of $\mathrm{Cd}$ improved with the increase of $\mathrm{Cd}$ treatment, and the concentration of $\mathrm{Cd}$ in seedling stage was much higher than that in maturity. It can be on account for the strong growth status, large demand for nutrients and lower plant biomass at the seedling stage. The content of $\mathrm{Cd}$ in the experimental group with the application of passivator DHJ-C was significantly lower than that of the control group at different periods and parts, and the highest was reduced by more than a half, indicating that the addition of DHJ-C can effectively reduce the availability of $\mathrm{Cd}$ ions in soil, and limit the accumulation of $\mathrm{Cd}$ in plant, which shows great application potential. Cd accumulation in rapeseeds, the index that attract the most attention, was not detect $(<0.1 \mathrm{mg} / \mathrm{kg})$ in all the experimental groups. Although the tested oilseed rape uptake a lot of $\mathrm{Cd}$ in roots and shoots, its mobility to seeds is perfectly safe, not to mention the addition of passivator DHJ-C. Therefore, it can be expected that the passivation agent DHJ-C will have great applied space and practical value in soils contaminated by Cd.

\section{Acknowledgements}

This work was supported by the Chinese National key R \& D program under Grant 2018YFC1802605.

\section{Authors' contributions}

XW mainly wrote this manuscript and conducted partial experiments. QL and YW conducted the experiments. CC was responsible for data analyzing and drawing. JB helped improving the manuscript. RW served as a consultant on experimental methods and techniques. YZ managed and organized full manuscript as a corresponding author. All authors read and approved the final manuscript.

\section{Declarations}

\section{Competing interests}

The authors declare no competing interests.

Received: 23 December 2020 Accepted: 25 February 2021

Published online: 03 March 2021

\section{References}

1. Huang B, Li ZW, Li DQ, Yuan ZJ, Nie XD, Huang JQ, Zhou YY (2019) Effect of moisture condition on the immobilization of $\mathrm{Cd}$ in red paddy soil using passivators. Environ Technol 40:2705-2714

2. Aitio A, Tritscher A (2004) Effects on health of cadmium - WHO approaches and conclusions. Biometals 17:491

3. Huang BF, Xin JL, Dai HW, Liu AQ, Zhou WJ, Yi YM, Liao KB (2015) Root morphological responses of three hot pepper cultivars to $\mathrm{Cd}$ exposure and their correlations with $\mathrm{Cd}$ accumulation. Environ Sci Pollut Res 22:1151-1159

4. Hassan W, Bano R, Bashir S, Aslam Z (2016) Cadmium toxicity and soil biological index under potato (Solanum tuberosum L.) cultivation. Soil Res 54:460-468

5. Khan A, Khan S, Khan MA, Qamar Z, Wagas M, Research P (2015) The uptake and bioaccumulation of heavy metals by food plants, their effects on plants nutrients, and associated health risk: a review. Environ Sci Pollut Res 22:13772-13799

6. Bandyopadhyay A, Mukherjee A (2011) Sensitivity of Allium and Nicotiana in cellular and acellular comet assays to assess differential genotoxicity of direct and indirect acting mutagens. Ecotoxicol Environ Saf 74:860-865

7. Helene LE, Bornman JF, Hakån A (1998) Influence of UV-B radiation and $\mathrm{Cd} 2+$ on chlorophyll fluorescence, growth and nutrient content in Brassica napus. J Exp Bot 49:1031-1039

8. Xue Z, Gao H, Zhao S (2014) Effects of cadmium on the photosynthetic activity in mature and young leaves of soybean plants. Environ Sci Pollut Res 21:4656-4664 
9. Leon A, Palma J, Corpas F (2002) Antioxidative enzymes in cultivars of pepper plants with different sensitivity to cadmium. Plant Physiol Biochem 40:813-820

10. Agrawal SB, Mishra S (2009) Effects of supplemental ultraviolet-B and cadmium on growth, antioxidants and yield of Pisum sativum L. Ecotoxicol Environ Saf 72:610-618

11. Sheng J, Lu WJ, Wang HT (2007) Effects of fly ash on the exchangeable heavy metals ( $\mathrm{Cu}, \mathrm{Zn}, \mathrm{Pb})$ during sewage sludge composting and land utilization. Huanjing Kexue 28:1367-1371

12. Fuentes A, Lloréns M, Sáez J, Aguilar MI, Meseguer VF (2004) Phytotoxicity and Heavy Metals Speciation of Stabilized Sewage Sludge. J Hazard Mater 108:161-169

13. Li H, Liu Y, Zhou YY et al (2018) Effects of red mud based passivator on the transformation of $\mathrm{Cd}$ fraction in acidic $\mathrm{Cd}$-polluted paddy soil and $\mathrm{Cd}$ absorption in rice. Sci Total Environ 640:736-745

14. Weng LF, Han LB, Chang ZH, Kong WC (2010) Physical and chemical properties of the soil in Chongqing Qinglong golf course greens. Acta Prataculturae Sinica 19:108-114

15. Sun JY, Li MZ, Zheng LH, Hu YG, Zhang XJ (2006) Real-time analysis of soil moisture, soil organic matter, and soil total nitrogen with NIR spectra. Spectrosc Spectr Anal 26:426-429

16. Yu Y, Chang T, Jian S, Qi W (2002) Spatial variability of soil organic matter total nitrogen, phosphorus and potassium in cotton field. Agri Res Arid Areas 20:26-30

17. Curtius AJ, Schlemmer G, Welz B (1987) Determination of phosphorus by graphite-furnace atomic-absorption spectrometry.2. comparison of different modifiers. J Anal At Spectrom 2:115-124

18. Caruso T, Hammer EC, Hempel S et al (2018) Assessing soil ecosystem processes-biodiversity relationships in a nature reserve in Central Europe. Plant Soil 424:491-501

19. Shi Y, Shi Y, Wang Y et al (2018) Dynamic responses of soil enzymes to exogenous sodium selenite and selenomethionine. Acta Sci Circum 38:1189-1196

20. Zhang X (1986) Determination of plant chlorophyll content by a mixture of acetone and ethanol. Liaoning Agri Sci 3:26-28
21. An M, Wei C, Wang K, Fan H, Wang X, Chang D (2021) Effects of polymer modifiers on the bacterial communities in cadmium-contaminated alkaline soil. Appl Soil Ecol. https://doi.org/10.1016/j.apsoil.2020.103777

22. Zaborowska M, Wyszkowska J, Kucharski J (2015) The possibilities of restoring the enzymatic balance of soil contaminated with cadmium. Int J Environ Pollut 58:197-214

23. Mohamed AA, Castagna A, Ranieri A, Toppi LSD (2012) Cadmium tolerance in Brassica juncea roots and shoots is affected by antioxidant status and phytochelatin biosynthesis. Plant Physiol Biochem 57:15-22

24. Ali B, Qian P, Jin R et al (2014) Physiological and ultra-structural changes in Brassica napus seedlings induced by cadmium stress. Biol Plant 58:131-138

25. Wu Z, Zhao X, Sun X et al (2015) Antioxidant enzyme systems and the ascorbate-glutathione cycle as contributing factors to cadmium accumulation and tolerance in two oilseed rape cultivars (Brassica napus L.) under moderate cadmium stress. Chemosphere 138:526-536

26. Yan H, Filardo F, Hu X, Zhao X, Fu DH (2016) Cadmium stress alters the redox reaction and hormone balance in oilseed rape (Brassica napus L.) leaves. Environ Sci Pollut Res 23:3758-3769

27. Jiang HD, Qin Z, Na LI, Sun XF (2006) Effect of Cd on the growth and physiological characteristics of rape seedlings. Chin J Oil Crop Sci 28:39-43

28. Gao M, Yang Y, Song Z (2019) Toxicity of cadmium to wheat seedling roots in the presence of graphene oxide. Chemosphere 233:9-16

29. Singh OV, Labana S, Pandey G, Budhiraja R, Jain RK (2003) Phytoremediation: an overview of metallic ion decontamination from soil. Appl Microbiol Biotechnol 61:405-412

30. Cui YJ, Zhang XH, Wang LM (2008) Transfer patterns of metal elements in soil-plant system in a contaminated area in Guangxi, China. Chin J Ecol 27:1822-1825

\section{Publisher's Note}

Springer Nature remains neutral with regard to jurisdictional claims in published maps and institutional affiliations.

\section{Submit your manuscript to a SpringerOpen ${ }^{\circ}$ journal and benefit from:}

- Convenient online submission

- Rigorous peer review

- Open access: articles freely available online

- High visibility within the field

- Retaining the copyright to your article

Submit your next manuscript at springeropen.com 